\title{
INVESTIGATION OF AN ALTERNATIVE TESTING PROTOCOL TO DETERMINE THE SHEAR STRENGTH OF BAMBOO PARALLEL TO THE GRAIN
}

\author{
Gabrielle Luisa Cantos ${ }^{1}$, Luis F. Lopez ${ }^{2}$, Richard M. de Jesus ${ }^{3, \star}$, Corinna Salzer ${ }^{2}$, \\ Lessandro E.O. Garciano
}

\begin{abstract}
The common testing protocol to determine the shear strength of bamboo parallel to grain is ISO 22157 (2004). However, widely documented limitations of this test procedure calls for an alternative testing protocol. This study compared ISO 22157 (2004) (TP1) and 2 alternative testing protocols proposed by Base Bahay (TP2a and 2b) in determining shear strength of bamboo parallel to grain. The study used a local bamboo known as "kawayang tinik" (Bambusa blumeana). Results showed that TP1 produced more pure shear failures at $65 \%$ compared to TP2a and TP2b at 55\% each. Shear strength values between the three methods were not significantly different, although, TP $2 \mathrm{~b}$ resulted in the lowest coefficient of variation at $18 \%$. Also, TP2b was found to be the most effective in terms of specimen preparation, ease of assembly of testing equipment, and low variability in data.
\end{abstract}

Keywords: Bambusa blumeana, Base Bahay method, ISO 22157, kawayang tinik, mechanical properties.

\section{INTRODUCTION}

Bamboo has been used as a construction material since early times. It has been used for floors, walls, ceilings, roofs, scaffoldings, bridges, and many others (Li 2004, Alipon et al. 2011, and Marquez 2006). The popularity of bamboo in construction is due to its desirable physical and mechanical properties. It is considered as one of the most important bio-based materials because of its renewability (Escamilla and Habert 2014). A bamboo plantation can grow as much as twenty-five centimeters per day and can be harvested every three to five years (Gutu 2013).

Because of these characteristics, bamboo is used as an alternative material for wood in developing countries (Cleuren 2003, Malab and Zafaralla 2006, and Marquez 2006). However, its proper utilization is hindered by lack of data and building codes (Sharma et al. 2015). Different species of bamboo have different physical and mechanical properties. These properties also vary along the culm of the bamboo (Oka et al. 2014).

Among the mechanical properties of bamboo, the shear strength parallel to the grain has the highest variability (Mitch 2009). ISO 22157 (2004) Bamboo - Determination of physical and mechanical properties is currently the common standard used to determine the physical and mechanical properties of bamboo, including shear strength parallel to the grain. The test makes use of a shearing tool designed by Janssen (1981). The shearing tool was designed to produce four shear planes of failure. However, Mitch (2009) showed that shear failure does not occur in all four planes. Also, this test results in a combined failure where pure shear failure is intended.

\footnotetext{
${ }^{1}$ Graduate student, Department of Civil Engineering, de La Salle University, Manila, Philippines.

${ }^{2}$ Consultant, Base Bahay Inc., Makati, Philippines.

${ }^{3}$ Faculty, Department of Civil Engineering, de La Salle University, Manila, Philippines.

•Corresponding author: richard.dejesus@dlsu.edu.ph
}

Received: 20.12.2017 Accepted: 16.07.2019 
As an effort to improve the results of shear test parallel to grain, this study investigated an alternative method to determine this property using a different shearing tool, and form of bamboo specimen. This alternative method was proposed by the engineers and researchers of Base Bahay, Inc.

\section{MATERIALS AND METHODS}

The shear strengths were obtained through experimentation following specific requirements and instructions from ISO 22157 (2004) for test protocol 1, and Base Bahay proposed and modified proposed method for test protocols $2 \mathrm{a}$ and $2 \mathrm{~b}$, respectively. Source of bamboo and its type were the same for all tests. The study investigated the effects of three different testing protocols for shear, and varying specimen height. In all test protocols employed in this study, a local bamboo known as kawayang tinik (Bambusa blumeana), was used as specimen sourced from Tarlac, Philippines. Twenty specimens were tested using ISO 22157 (2004) test protocol, while a total of 40 specimens were tested for both alternative testing protocols: (1) proposed Base Bahay method, and (2) a modification of Base Bahay method.

\section{ISO 22157 - Test protocol 1 (TP1)}

In compliance with ISO 22157 (2004), the shearing tool used for this method is shown in Figure 1a, while the bamboo specimen used is shown in Figure 1b. The bamboo specimen is a round of bamboo with a length equal to the lesser value between the diameter, $\mathrm{D}$, and ten times the wall thickness, 10t. A Universal Testing Machine (UTM) with a load rate of $0,01 \mathrm{~mm} / \mathrm{sec}$ was used for load application. The set-up is shown in Figure $1 \mathrm{c}$.

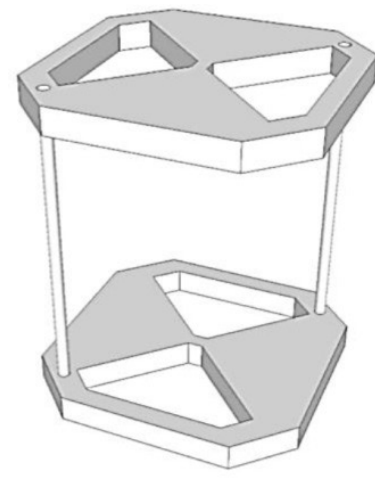

(a) Shearing tool

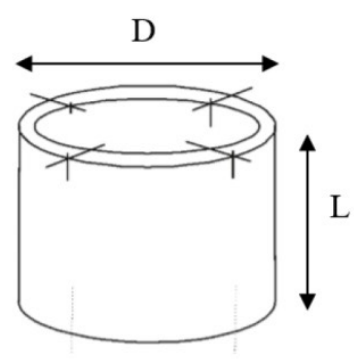

(b) Specimen

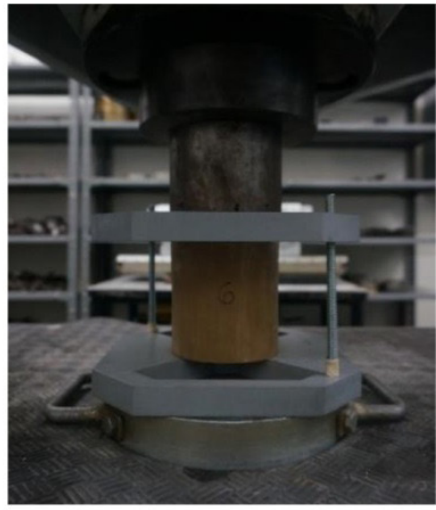

(c) Set-up

Figure 1: Materials and set-up for ISO 22157 (2004) (TP1).

\section{Base Bahay proposed method (TP2a) and modified Base Bahay proposed method (TP2b)}

The alternative method, both for TP2a and TP2b, made use of a different shearing tool and bamboo specimen form (Figure 2a). The shearing tool was designed in such a way that two shear planes of failure were produced. The bamboo specimen was half a round of bamboo with a constant length of $80 \mathrm{~mm}$ for TP2a (Figure $2 \mathrm{~b}$ ) while length of $50 \mathrm{~mm}$ is considered for TP2b. This difference in specimen length size is the only difference between TP2a and TP2b. A UTM capable of providing a load rate of $0,01 \mathrm{~mm} / \mathrm{sec}$ was also used. The set-up is shown in Figure 2c. 


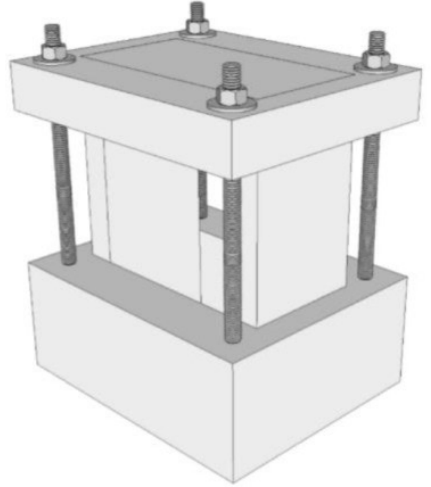

(a) Shearing tool
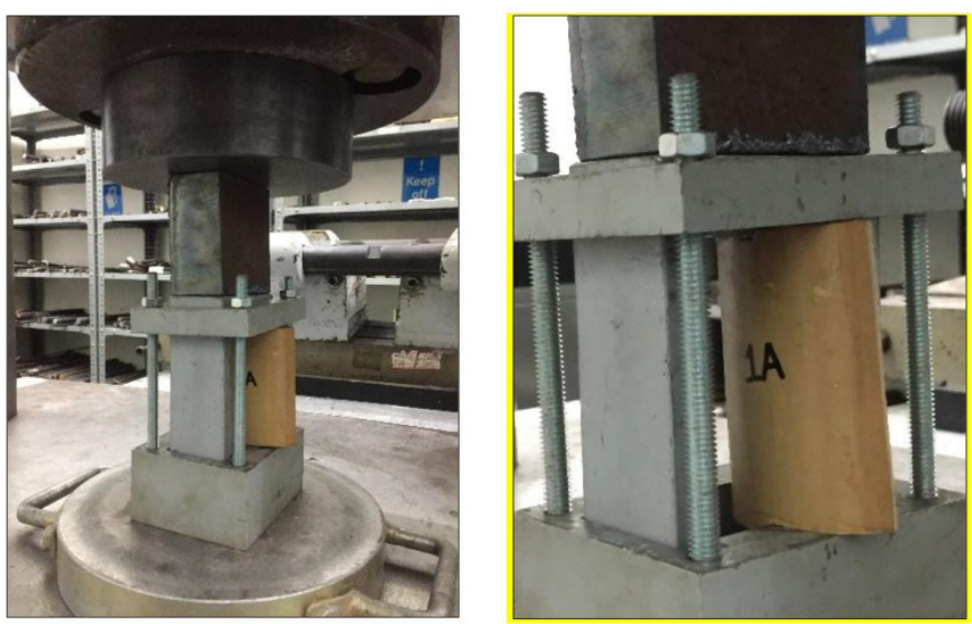

(c) Test set-up

Figure 2: Materials and set-up for Base Bahay Protocol (TP2a and TP2b).

To calculate the shear strength of bamboo parallel to the grain, a Universal Testing Machine (UTM) was used to determine the load at failure and a digital Vernier caliper was used to measure the area of the planes of failure. The moisture content and mass per volume were determined after the shear test of each specimen. The moisture content was determined using the oven dry method and the mass per volume was determined by measuring the dimensions of a small sample of each specimen using a digital Vernier caliper. ANOVA (Analysis of Variance) was used for analysis and comparison of data.

\section{RESULTS AND DISCUSSION}

\section{Bamboo specimen}

The form of the bamboo specimen was found to have significant effects on the mode of failure and shear strength. The varying geometrical properties of bamboo in the longitudinal, radial, and transverse directions made it difficult to fabricate symmetrical specimens (Sharma et al. 2015), especially for specimens for TP1. In TP1, it is crucial to ensure that specimens have parallel end planes which are perpendicular to the grain of failure. Unparallel end planes result to uneven distribution of load and errors in test results. This requirement 
was not crucial for specimens for TP2a and TP2b, thus, easier to fabricate.

\section{Shearing tool}

The shearing tool for TP1 was easy to fabricate and provides a 360-degree view of the bamboo specimen during experimentation. However, its two plates were difficult to align, compromising the occurrence of pure shear failure. The shearing tool for both TP2a and TP2b was easier to align. Although, there was a tendency of friction to occur because of the physical contact of plates.

\section{Mode of failure}

Three modes of failure occurred (Figure 3) during the course of experiment for three test protocols: (1) shear parallel to the grain, (2) compression parallel to the grain, and (3) tension due to bending. The occurrence of each failure mode for the two methods are summarized in Table 1 . TP1 resulted in $65 \%$ shear failure, $30 \%$ compression failure, and 5\% tension due to bending. TP2a resulted in 55\% shear failure, $35 \%$ compression failure, and $10 \%$ tension due to bending.

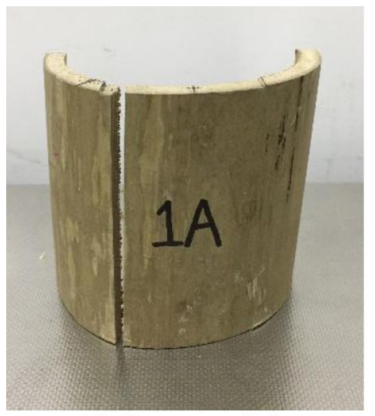

(a) Shear parallel to grain

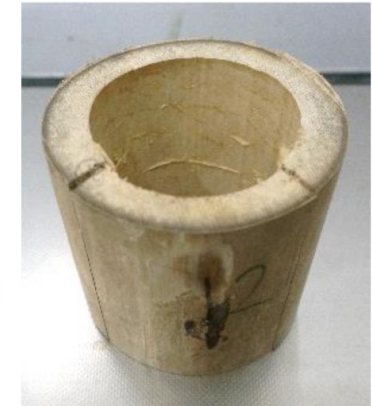

(b) Compression

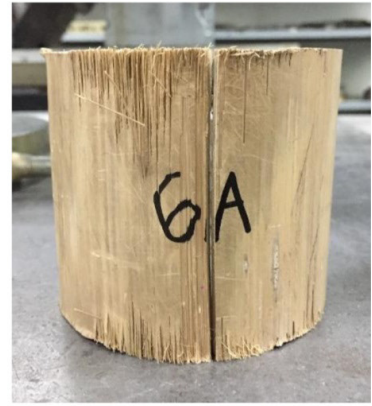

(c) Tension due to bending

Figure 3: Modes of failure.

Table 1: Summary of modes of failure for Test Protocols $1 \& 2$ a.

\begin{tabular}{|l|c|c|c|c|}
\hline \multirow{2}{*}{ Mode of Failure } & \multicolumn{2}{c|}{ No. of Specimens } & \multicolumn{2}{c|}{ Percentage } \\
\cline { 2 - 5 } & TP1 & TP2a & TP1 & TP2a \\
\hline Shear & 13 & 22 & 65 & 55 \\
\hline Compression & 6 & 14 & 30 & 35 \\
\hline Tension Due to Bending & 1 & 4 & 5 & 10 \\
\hline Total & 20 & 40 & 100 & 100 \\
\hline
\end{tabular}

To further increase the likelihood of shear failure for TP2a, forty additional tests were conducted using the same procedure, the same shearing tool, and a different specimen length. The length of the bamboo specimen was reduced from $80 \mathrm{~mm}$ to $50 \mathrm{~mm}$. Reducing the length of the specimen would reduce the total shear area, and would therefore theoretically increase the likelihood of shear failure. This new set of tests is TP2b. The results are found in Table 2. It can be seen, however, that despite the reduction of specimen length, the occurrence of shear failure remained at $55 \%$.

Table 2: Summary of modes of failure for Protocol 1, 2a, \& 2b.

\begin{tabular}{|l|c|c|c|c|c|c|}
\hline \multirow{2}{*}{ Mode of Failure } & \multicolumn{3}{|c|}{ No. of Specimens } & \multicolumn{3}{c|}{ Percentage (\%) } \\
\cline { 2 - 7 } & TP 1 & TP2a & TP2b & TP1 & TP2a & TP2b \\
\hline Shear & 13 & 22 & 22 & 65 & 55 & 55 \\
\hline Compression & 6 & 14 & 4 & 30 & 35 & 10 \\
\hline Tension Due to Bending & 1 & 4 & 14 & 5 & 10 & 35 \\
\hline Total & 20 & 40 & 40 & 100 & 100 & 100 \\
\hline
\end{tabular}


The dominant mode of failure for all three protocols is shear parallel to the grain. However, the occurrence of other modes of failure such as compression parallel to the grain and tension due to bending were not avoided. These were attributed to the crooked nature of bamboo and the unparallel end planes of the specimen, which then cause uneven distribution of load. TP2a and TP2b both resulted in 55\% shear failure. The second dominant mode of failure for TP2a is compression parallel to the grain and is attributed to the length of the specimen at $80 \mathrm{~mm}$, which made the specimen slender and likely to buckle. On the other hand, the second dominant mode of failure for TP $2 b$ is tension due to bending. Since the length of the specimen was reduced to $50 \mathrm{~mm}$, buckling was avoided, although tension due to bending occurred.

\section{Shear strength}

For the statistical analysis, only specimens that failed in shear were considered. The number of specimens considered for each method can be seen in Table 3 along with other statistical data. The results of the experiment showed that the shear strength of bamboo parallel to the grain has an average value of $8,80 \mathrm{MPa}$ for TP1 9,81 MPa for TP2a, and 9,50 MPa for TP2b. The values range from 4,38-13,91 MPa for TP1, 5,60-13,45 MPa for TP2a, and 5,99-13,01 MPa for TP2b. The values obtained from the study are comparable to the values obtained by Janssen (1981) and Mitch (2009). Janssen conducted tests on the same specie of bamboo (Bambusa blumeana). The average shear strength from his study is 10,26 MPa. On the other hand, Mitch conducted tests on Bambusa stenostachya wherein the average shear strength is $8,8 \mathrm{MPa}$.

In the Philippine setting, the closest data is from the study of Alipon et al. (2011) where Dendrocalamus asper from Malaybalay, Bukidnon and Mt. Makiling, Laguna were used. In their study, the average shear strength of bamboo parallel to the gain is 8,31 MPa for samples from Malaybalay and 3,18 MPa for samples from Mt. Makiling. The values range from 6,39-10,26 MPa and 2,49-4,04 MPa for Malaybalay and Mt. Makiling, respectively. The shear strength of Bambusa blumeana obtained from this study is close to that of Dendrocalamus asper from Malaybalay.

Analysis of variance (ANOVA) showed no significant differences among the shear strength values between TP1, TP2a, and TP2b. TP1 resulted in the highest coefficient of variation at 35,40\%, while TP2b method resulted in the lowest coefficient of variation at $18,00 \%$.

Table 3: Summary of statistical analysis of shear tests results.

\begin{tabular}{|l|c|c|c|c|c|c|}
\hline Groups & $\begin{array}{c}\text { No. of } \\
\text { Samples }\end{array}$ & $\begin{array}{c}\text { Range } \\
\text { (MPa) }\end{array}$ & $\begin{array}{c}\text { Average } \\
\text { (MPa) }\end{array}$ & StDev & Variance & $\begin{array}{c}\text { Coefficient of } \\
\text { Variation (\%) }\end{array}$ \\
\hline TP1 & 13 & $4,38-13,91$ & 8,80 & 3,12 & 9,72 & 35,40 \\
\hline TP2a & 22 & $5,60-13,45$ & 9,81 & 1,99 & 3,98 & 20,33 \\
\hline TP2b & 22 & $5,99-13,01$ & 9,50 & 1,71 & 2,92 & 18,00 \\
\hline
\end{tabular}

TP1 has a mean value of $8,80 \mathrm{MPa}$ and a confidence interval of 7,26 to $10,34 \mathrm{MPa}$. TP2a has a mean value of 9,81 $\mathrm{MPa}$ and a confidence interval of 9,08 to $10,55 \mathrm{MPa}$. TP2b has a mean value of 9,50 MPa and a confidence interval of 8,87 to $10,12 \mathrm{MPa}$. There is $95 \%$ confidence that the value of the shear strength of Bambusa blumeana from Tarlac is found within these ranges. The characteristic shear strengths of bamboo are 3,82 $\mathrm{MPa}, 6,41 \mathrm{MPa}$, and 5,96 MPa for test protocols $1,2 \mathrm{a}$, and 2b, respectively. These values represent the shear strengths of bamboo that more than $95 \%$ of samples can endure. Using the equation for allowable stress found in ISO 22156, the allowable strengths are 1,27 MPa, 2,13 MPa, and 1,98 MPa for test protocols $1,2 \mathrm{a}$, and $2 \mathrm{~b}$, respectively. The characteristic shear strength and the allowable strength for TP1 resulted in the lowest values among all protocols.

\section{CONCLUSIONS}

ISO 22157 (2004) test protocol (TP1) resulted in 65\% pure failure, the most among the three test protocols investigated in this study. The average shear strength obtained was $8,80 \mathrm{MPa}$ with a coefficient of variation of $35,40 \%$. The occurrence of other modes of failure such as compression and tension due to bending were attributed to the crooked nature of bamboo and the difficulty to make even and straight specimens. On the 
other hand, the proposed method of Base Bahay (TP2a) resulted in 55\% pure shear failure. The average shear strength is $9,81 \mathrm{MPa}$ with a coefficient of variation of $20,33 \%$. The outcome of pure shear failure was lower compared to TP1. Reduction of specimen length from $80 \mathrm{~mm}$ to $50 \mathrm{~mm}$ (TP2b) did not increase the likelihood of failing due to shear which remained at $55 \%$, similar to that of TP2a. The coefficient of variation decreased to $18 \%$ with an average shear strength of $9,50 \mathrm{MPa}$. ANOVA (analysis of variance) exhibited no significant differences between the shear strengths of TP1, TP2a, and TP2b.

Although the occurrence of other modes of failure was not resolved by the Base Bahay proposed method, it was able to decrease variability because of the reduced number of intended planes of failure. Also, the specimen for the Base Bahay method was easier to fabricate, and the shearing tool was easier to assemble for experimentation. This can be the basis for future studies which aim to improve the shear test of bamboo parallel to the grain. It is recommended to study other forms of specimens for the Base Bahay shearing tool, and also to quantify the level of crookedness of these specimens.

\section{REFERENCES}

Alipon, M.A.; Bondad, E.O.; Sapin, G.N.; Exconde, A.B. 2011. Comparative physical and mechanical properties of giant bamboo from Malaybalay, Bukidnon and Mt. Makiling, Laguna. Philippine Forest Products Journal 2: 84-98.

Cleuren, H.; Henkemans, A. 2003. Development of the bamboo sector in Ecuador: harnessing the potential of Guadua angustifolia. J Bamboo and Rattan 2(2): 179-188.

Escamilla, E.; Habert, G. 2014. Environmental impacts of bamboo-based construction materials representing global production diversity. Journal of Cleaner Production 69: 117-127.

Gutu, T. 2013. A study on the mechanical strength properties of bamboo to enhance its diversification on its utilization. International Journal of Innovative Technology and Exploring Engineering 2(5): 314-319.

ISO. 2004. Bamboo - Structural design. ISO 22156. 2004. Geneva, Switzerland: ISO/IEC.

ISO. 2004. Bamboo - determination of physical and mechanical properties. ISO 22157. 2004. Geneva, Switzerland: ISO/IEC.

Janssen, J. 1981. Bamboo in building structures. Eindhoven: Technische Hogeschool Eindhoven DOI: $10.6100 /$ IR11834.

Li, X. 2004. Physical, chemical, and mechanical properties of bamboo and its utilization potential for fiberboard manufacturing. Master's thesis, Louisiana State University, United States. Available from https:// digitalcommons.lsu.edu/gradschool_theses/866/.

Malab, S.; Zafaralla, J. 2006. Engineered kawayan technology promotion and investment options for commercialization (Monograph). Batac, Ilocos Norte: Mariano Marcos State University. 11p.

Marquez, C. 2006. Improving and maintaining productivity of Bambusa blumeana for quality shoots and timber in Iloilo and Capiz, the Philippines. Australian Centre for International Agricultural Research: Canberra. $46-60$.

Mitch, D. 2009. Splitting capacity characterization of bamboo culms. Undergraduate thesis, University of Pittsburgh, United States. Available from <http://d-scholarship.pitt.edu/6704/>.

Oka, G.; Triwiyono, A.; Awaludin, A.; Siswosukarto, S. 2014. Effects of node, internode, and height position on the mechanical properties of gigantochloa atriviolacea bamboo. Procedia Engineering 95: 3137. Available from https://doi.org/10.1016/j.proeng.2014.12.162.

Sharma, B.; Gatoo, A.; Bock, M.; Ramage, M. 2015. Engineered bamboo for structural applications. Construction and Building Materials 81: 66-73. 